\title{
Ares I-X Upper Stage Simulator Compartment Pressure Comparisons during Ascent
}

\author{
William J. Downs ${ }^{1}$ \\ NASA George C. Marshall Space Flight Center, Huntsville, AL, 35812 \\ Robert D. Kirchner ${ }^{2}$ \\ Qualis Corporation, Jacobs ESTS Group, Huntsville, AL, 35806 \\ Lawrence A. Hand ${ }^{3}$ \\ NASA Ames Research Center, Moffett Field, CA, 94035 \\ Blair G. McLachlan ${ }^{4}$ \\ NASA Ames Research Center, Moffett Field, CA, 94035 \\ and \\ Stuart L. Nelson ${ }^{5}$ \\ NASA George C. Marshall Space Flight Center, Huntsville, AL, 35812
}

Predictions of internal compartment pressures are necessary in the design of interstage regions, systems tunnels, and protuberance covers of launch vehicles to assess potential burst and crush loading of the structure. History has proven that unexpected differential pressure loads can lead to catastrophic failure. Pressures measured in the Upper Stage Simulator (USS) compartment of Ares I-X during flight were compared to post-flight analytical predictions using the CHCHVENT chamber-to-chamber venting analysis computer program. The measured pressures were enveloped by the analytical predictions for most of the first minute of flight but were outside of the predictions thereafter. This paper summarizes the venting system for the USS, discusses the probable reasons for the discrepancies between the measured and predicted pressures, and provides recommendations for future flight vehicles.

\section{Nomenclature}

$A \quad=$ vent area, $\mathrm{ft}^{2}$

$A^{*} \quad=$ sonic flow vent area, $\mathrm{ft}^{2}$

$\alpha=$ trajectory angle of attack, degrees

$\beta=$ trajectory angle of sideslip, degrees

$C_{d} \quad=$ vent discharge coefficient

$C_{p L} \quad=$ local pressure coefficient

$\gamma=$ ratio of specific heats

$h \quad=$ trajectory altitude, $\mathrm{ft}$

${ }^{1}$ Aerospace Engineer, Aerosciences Branch/MS EV33.

${ }^{2}$ Aerospace Engineer, Aerosciences Branch/MS EV33, AIAA Senior Member.

${ }^{3}$ Aerospace Engineer, Experimental Aero-Physics Branch/MS 260-1.

${ }^{4}$ Aerospace Engineer, Experimental Aero-Physics Branch/MS 260-1, AIAA Senior Member.

${ }^{5}$ Aerospace Engineer, Aerosciences Branch/MS EV33. 


$\begin{array}{ll}\varphi & =\text { azimuthal position, degrees } \\ \dot{m} & =\text { mass flow rate, slugs } / \mathrm{s} \\ M_{\infty} & =\text { trajectory Mach number } \\ P_{L} & =\text { local external surface pressure, } \mathrm{lbf} / \mathrm{ft}^{2} \\ P_{C} & =\text { compartment pressure, } 1 \mathrm{bf} / \mathrm{ft}^{2} \\ P_{\infty} & =\text { free-stream static pressure, } \mathrm{lbf} / \mathrm{ft}^{2} \\ q_{\infty} & =\text { free-stream dynamic pressure, } \mathrm{lbf} / \mathrm{ft}^{2} \\ R & =\text { gas constant, } \mathrm{ft}^{2} /\left(\mathrm{s}^{2} \cdot{ }^{\circ} \mathrm{R}\right) \\ t & =\text { trajectory time, } \mathrm{s} \\ T_{C} & =\text { compartment temperature, }{ }^{\circ} \mathrm{R} \\ x / d & =\text { normalized axial location }\end{array}$

\section{Introduction}

T aunch vehicle internal compartments and protuberances are typically vented to provide an escape for purge

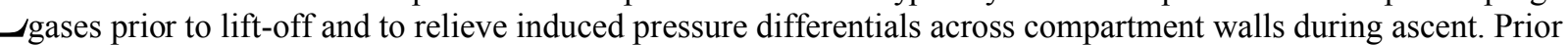
to launch, purge systems are generally used to remove hazardous gases as well as aid in temperature and humidity control of the compartment. Most compartments contain gas at essentially sea-level barometric conditions at lift-off. During ascent, the launch vehicle experiences a decrease in atmospheric pressure to practically zero within the first few minutes of flight, and differential pressures across the vehicle walls are induced. Internal compartment pressures can be controlled to some extent with vents, whereas local external pressures are dictated by vehicle geometry and flight trajectory. Magnitudes of the differential pressures are required so appropriate structural integrity can be designed into the vehicle. Ascent venting analyses are generally performed to predict internal compartment pressures, which can be coupled with the external pressures to yield skin differentials.

As part of the development of the next generation of human-rated launch vehicles under the National Aeronautics and Space Administration's (NASA) Constellation Program, a series of un-manned flight tests were planned. The first fully integrated launch vehicle flight test, Ares I-X, was launched on 28 October 2009 from NASA's Kennedy Space Center. Numerous measurements were taken during flight for verification and validation of methods used in predicting Ares I flight environments.

The Ares I-X USS was constructed with virtually its entire interior volume comprising a single compartment; whereas, the Ares I integrated Upper Stage (US) design consists of multiple compartments. In addition, there were differences in the design and location of the compartment vents and their positions relative to protuberances. Nevertheless, the Ares I-X flight provided an opportunity to obtain flight data for use in analytical model validation and development. The primary emphasis of the flight evaluation was to compare the measured internal USS compartment pressures to analytical predictions. The goals were to validate the approach being used to develop ascent venting environments for the Ares I integrated US compartments and make necessary adjustments to the approach based on the flight evaluation.

\section{Inputs to USS Venting Environments}

The primary inputs to any vehicle compartment venting analysis include external surface pressures, vehicle trajectory, volumes, vent/leak areas, and the flow characteristics thereof (e.g., discharge coefficients). Vehicle external surface pressure coefficients were obtained from post-flight computational fluid dynamic (CFD) analyses of the Ares I-X configuration using the USM3D program and conditions from the Ares I-X Best Estimated flight Trajectory (BET). Local absolute external pressures on the surface were calculated from the definition of the pressure coefficient given in Eq. (1).

$$
P_{L}(t)=C_{p L}\left(M_{\infty}, \alpha, \beta, x / d, \varphi\right) \cdot q_{\infty}\left(P_{\infty}, M_{\infty}\right)+P_{\infty}(h)
$$

Figure 1 depicts the major elements of the Ares I-X vehicle. The Command Module (CM)/Launch Abort System (LAS) simulator, Upper Stage Simulator (USS), and First Stage (FS) Frustum elements comprised a single volume. ${ }^{1}$ This volume is referred to herein as the "USS Compartment" as indicated in Figure 1.

The USS compartment was constructed with eight vents, all of which were located at the approximate axial station depicted in Figure 1. The vents were evenly distributed circumferentially in pairs as indicated in Figure 2. Schematics of the vent assembly and a photograph (looking towards the nose of the vehicle) of a pair of vents are provided in Figure 3. Moving from inside to outside of the vehicle, each USS vent assembly consisted of a 
rectangular entrance duct which transitioned to a circular cross-section through an eccentric reducer. The eccentric reducer was attached to a flange, which attached to the inner surface of the USS. A screen was positioned near the vehicle outer mold line (OML) to prevent entry of foreign objects. A free-hanging, one-way flapper door was placed in the rectangular section to prevent ingestion of ambient air. Wiring for developmental flight instrumentation (DFI), consisting of a gas temperature probe (GTP) located in the vent duct and a thermocouple mounted on the underside of the rectangular vent housing, can be observed in the upper right-hand and lower insets of Figure 3.

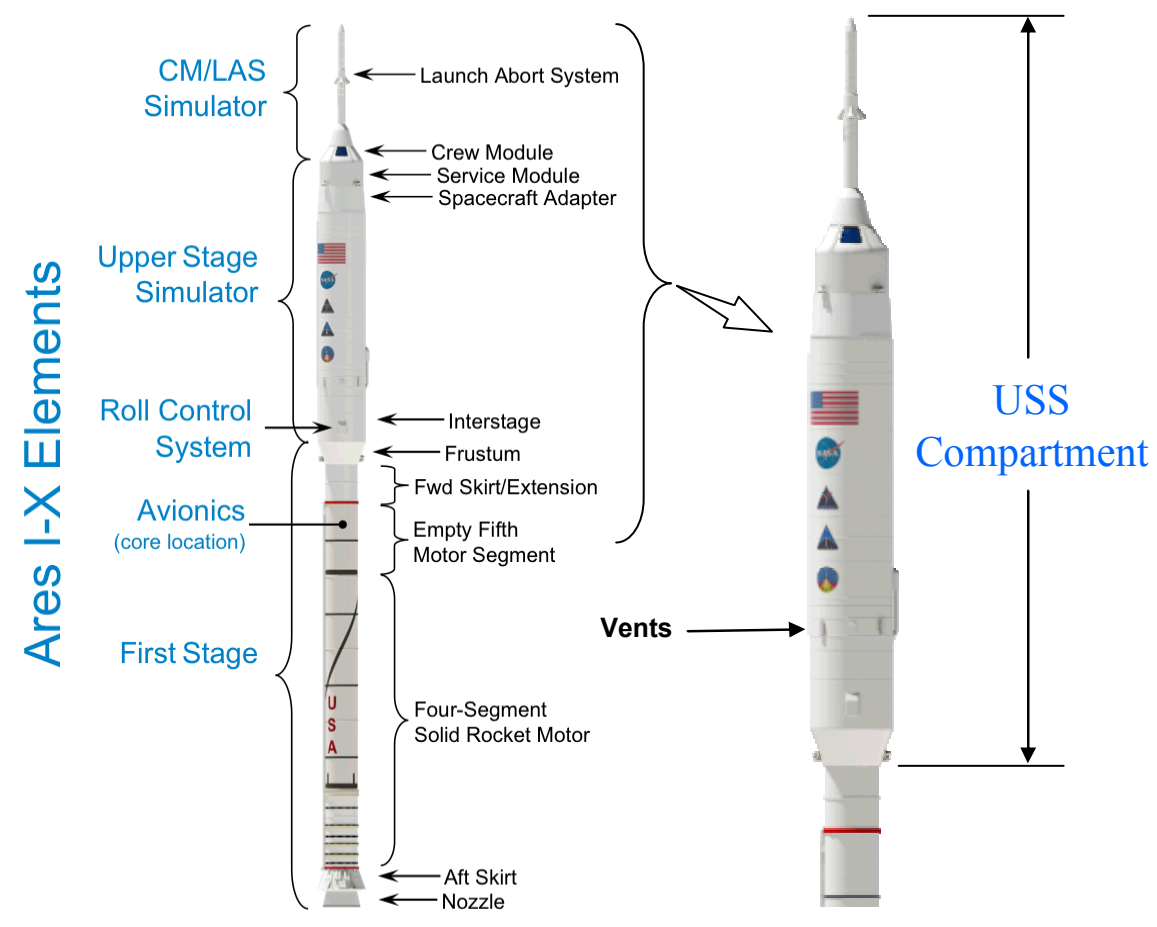

Figure 1. Ares I-X vehicle and USS compartment

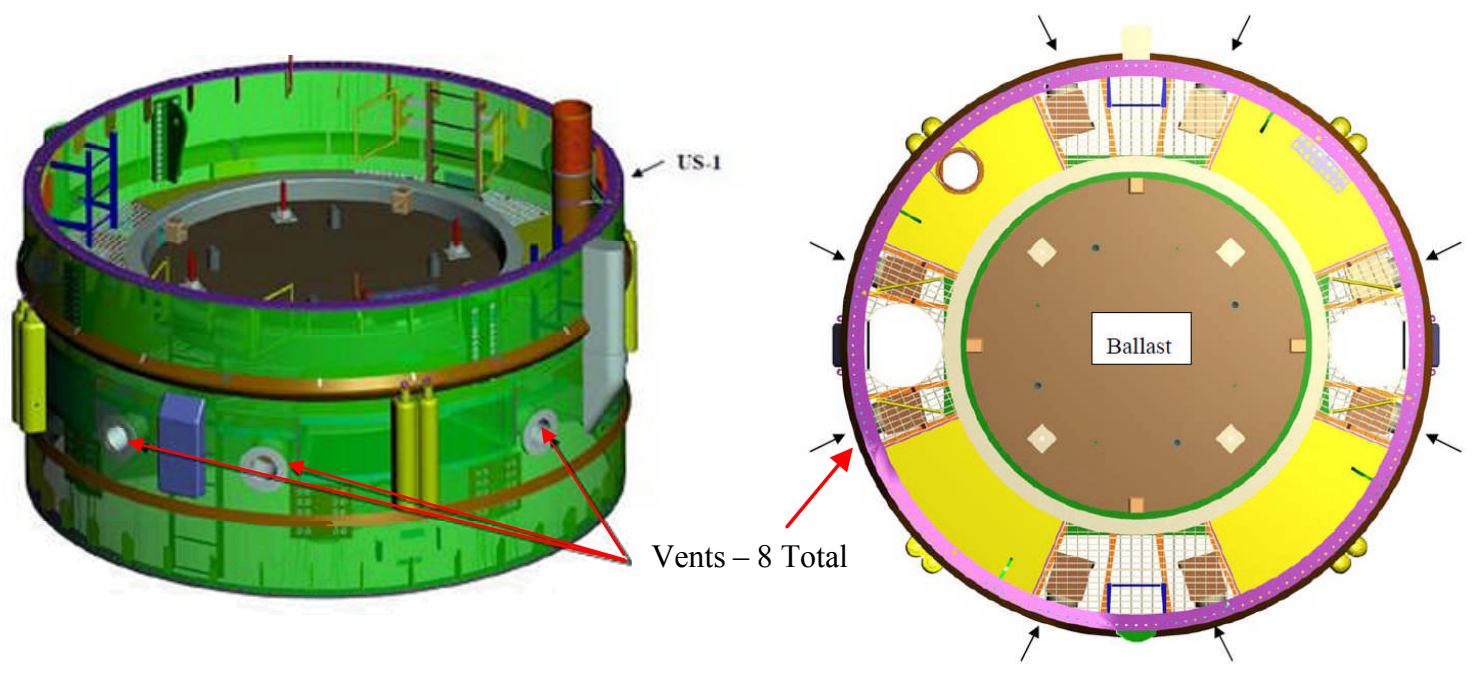

Figure 2. Ares I-X USS vent locations 


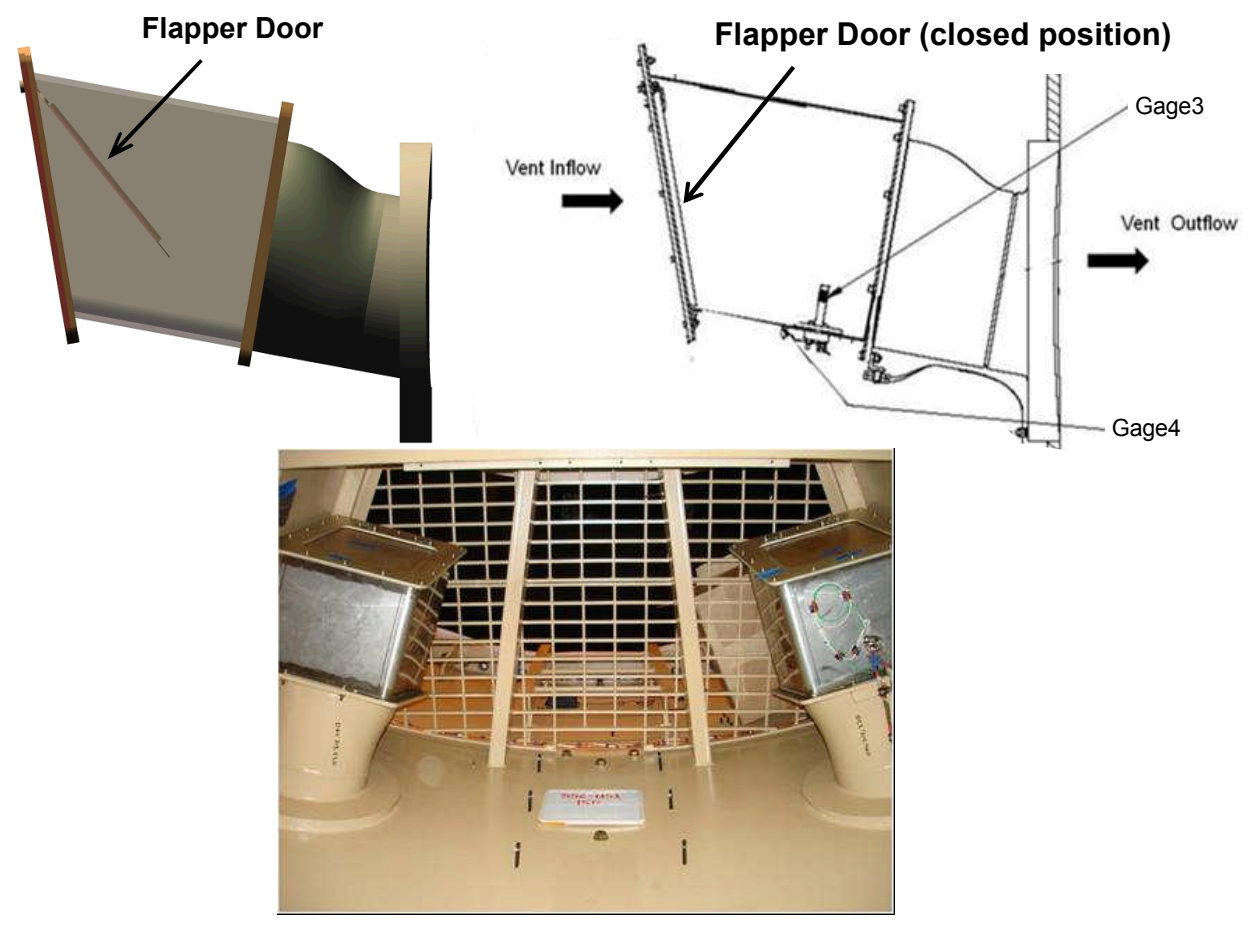

Figure 3. Ares I-X USS vent assemblies

\section{Venting Environments Development Approach}

The computer program, CHCHVENT $^{2}$ was used to develop the analytical predictions. The program models transient flow in an arbitrary arrangement of compartments and vents. Mass and energy fluxes for each compartment are computed using the current thermodynamic state of the system. The program advances in time by numerical integration, and the state of each compartment is updated at each time interval. CHCHVENT computes the mass flow rate though each vent as the ideal theoretical mass flow rate (one-dimensional isentropic flow into still air at the local external surface pressure) corrected with a discharge coefficient to account for jet contraction, jet/cross-flow interaction, and viscous losses.

Two analysis cases were used to develop a "design band" with the goal of bounding the USS compartment pressures. Specific modeling assumptions were used to predict the maximum internal compartment pressures during ascent. These pressures can be combined with the minimum external wall pressures to also determine the maximum skin differential pressures. Different modeling assumptions were used to predict the minimum internal compartment pressures during ascent, and these can be combined with the maximum external pressures to determine the minimum skin differential pressures.

A model consisting of a single compartment with eight vents was used in the analysis. Leakage in the structure around joints, penetrations, etc. was not specified or known; therefore, zero structural leakage was assumed. Following practices used for Ares I, the compartment volume was increased by $10 \%$ for the maximum pressure case and decreased by $10 \%$ for the minimum pressure case.

The vent discharge coefficients used are functions of the compartment-to-local surface pressure ratio $\left(\mathrm{P}_{\mathrm{C}} / \mathrm{P}_{\mathrm{L}}\right)$ and the local cross-flow Mach number $\left(\mathrm{M}_{\mathrm{L}}\right)$ at the vent. They were derived from a series of wind-tunnel tests previously conducted to determine the outflow and inflow discharge coefficients for orifices with pressure ratios between approximately 0.5 and 2 and cross-flow Mach numbers of 0.7 to 1.9. ${ }^{3,4}$ Thin-plate orifices of different shapes (e.g., circular and elliptical) and orientations to the oncoming tunnel flow were tested under boundary layers of various thicknesses. Minimum and maximum bounding curves on the discharge coefficients were constructed from the experimental data for the circular orifices. These curves were combined with no-crossflow $\left(\mathrm{M}_{\mathrm{L}}=0\right)$ pressuredependent discharge coefficients ${ }^{5}$ and translated into look-up tables used by CHCHVENT. 


\section{Developmental Flight Instrumentation (DFI)}

Flight measurements used in this study are listed in Table 1, and the approximate locations of the sensors are depicted on the CFD model in Figure 4. The upper inset shows the location of the compartment vents and the two internal compartment pressure sensors, Gage1 and Gage2. The lower inset depicts the opposite side of the vehicle and also shows the compartment vents and the locations of the external pressure sensors, Gage5 and Gage6, used to compare to the CFD data.

\section{Comparisons}

\section{A. External Surface Pressures}

Local surface pressures in the immediate vicinity of the vents were not recorded during flight. Figures 5 and 6 compare pressures from the BET-specific CFD solutions to flight measured pressures at corresponding locations. [Note: The absolute scales of the plot vertical axes have been removed to comply with program restrictions.] Gage5 had a small range at the request of the aerothermal team, which resulted in the "flat-line" data for the first 65 seconds of flight. Good agreement between the flight data and CFD solutions can be observed for the time interval after 65 seconds. Comparisons of CFD data and measurements from Gage 6 are provided in Figure 6. This gauge was also requested by the aerothermal team and had a limited pressure range, again resulting in "flatline" data for the initial flight phase. Figure 6 shows that the CFD surface pressures are in good agreement with the flight data after approximately 45 seconds. Based on the comparisons for these two sensors, confidence that pressures at the USS vent locations could be adequately predicted with the CFD analyses was increased. It should be noted, however, that Gage5 and Gage6 were located in clean-skin areas, where the USS vents were located around protuberances as depicted in Figure 2.

\section{B. Internal Compartment Pressures}

Two pressure transducers, Gage1 and Gage2, were mounted inside the USS compartment in the approximate positions indicated in Figure 4 to obtain the compartment pressures during ascent. Sensors with a range of 0-25 psia were used and ranged by the data acquisition software (gain and

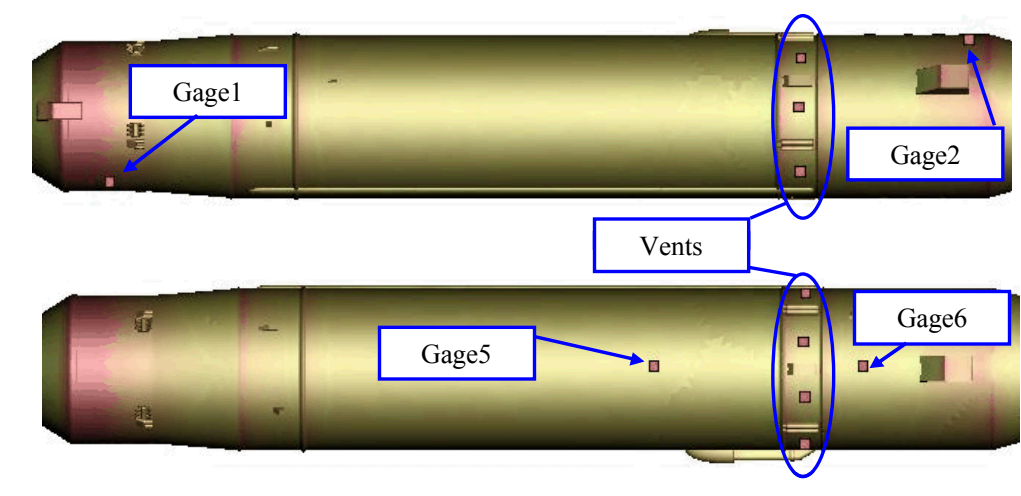

Figure 4. Ares I-X USS DFI

\begin{tabular}{|l|c|c|c|}
\hline \multicolumn{1}{|c|}{ Sensor } & Body Part & Location & Sensor Type \\
\hline Gage1 & USS compartment & interior & pressure \\
\hline Gage2 & USS compartment & interior & pressure \\
\hline Gage3 & vent assembly & duct interior & gas temp probe \\
\hline Gage4 & vent assembly & duct surface & thermocouple \\
\hline Gage5 & US segment & surface & pressure \\
\hline Gage6 & US segment & surface & pressure \\
\hline
\end{tabular}

Table 1. Ares I-X Developmental Flight Instrumentation (DFI) used in ascent venting flight evaluation of USS compartment

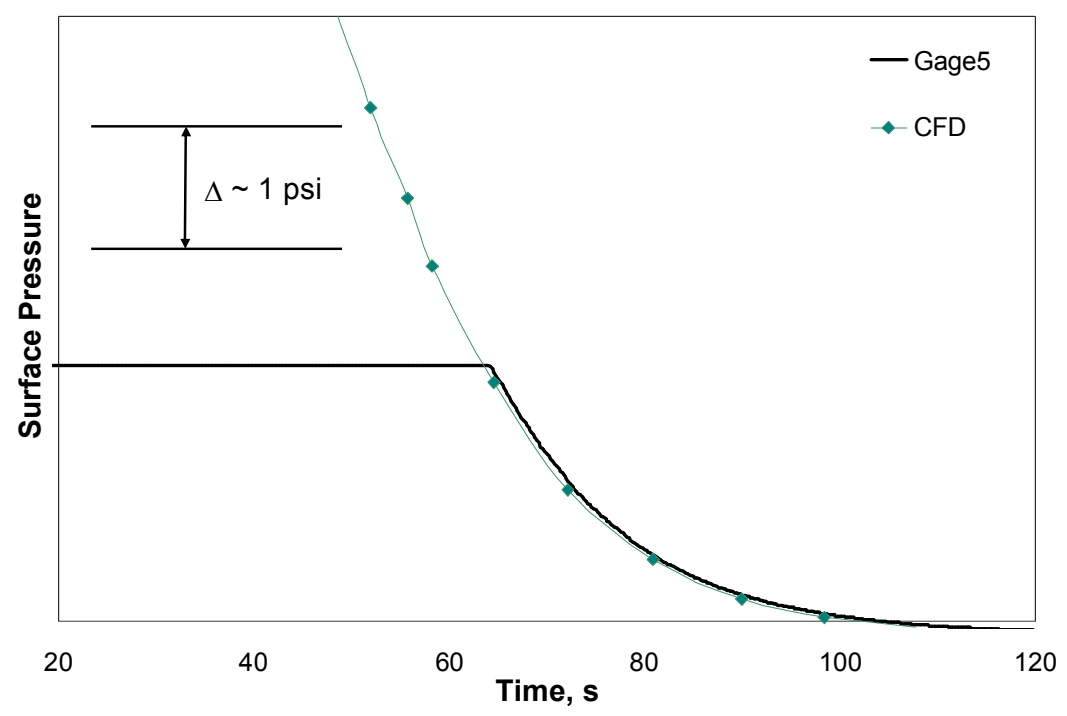

Figure 5. Comparisons of Gage5 and CFD 
offset) for a full-scale reading of 0-15 psia. The accuracy for these two measurements was documented through analysis, not test. Calculations were based on sensor and data system specifications, but did not include possible errors caused by installation effects, such as cable run impedance and housing deformation on the sensing element and/or environmental factors such as noise and thermal effects. The estimated uncertainties for these two measurements were $+/-0.51 \%$ of full scale, which results in an uncertainty for each measurement given by Eq. (2).

$$
15 \text { psia } \cdot( \pm 0.51 / 100)= \pm 0.08 \text { psi }
$$

Data from the two gauges were compared and the maximum differences were within the estimated uncertainty (i.e., $2 \cdot 0.08 \mathrm{psi}=0.16$ psi). Gage2 was used in the comparisons herein because of a noted anomaly with Gage1 during pre-flight check-out.

Three different sets of analytical predictions of Ares I-X USS compartment pressures were developed at three different times in the program. Preliminary design environments were developed two years prior to flight, and pre-flight predictions were generated just weeks prior to flight. Analyses were updated after the flight to incorporate the BET and BET-specific CFD data for the Ares I-X configuration, whereas preliminary design and pre-flight predictions were based on Ares I CFD solutions. The post-flight analyses are believed to include the most accurate surface pressures and are thus considered the best set of analytical data with which to compare to flight data.

Comparisons of measured USS internal compartment pressures with post-flight analyses are provided as functions of flight time and Mach number in Figures 7 and 8, respectively. Each figure includes predictions from both the maximum and minimum pressure analysis cases. The predicted compartment pressures from the maximum pressure case exceeded the flight data for the first 75 seconds but were below the

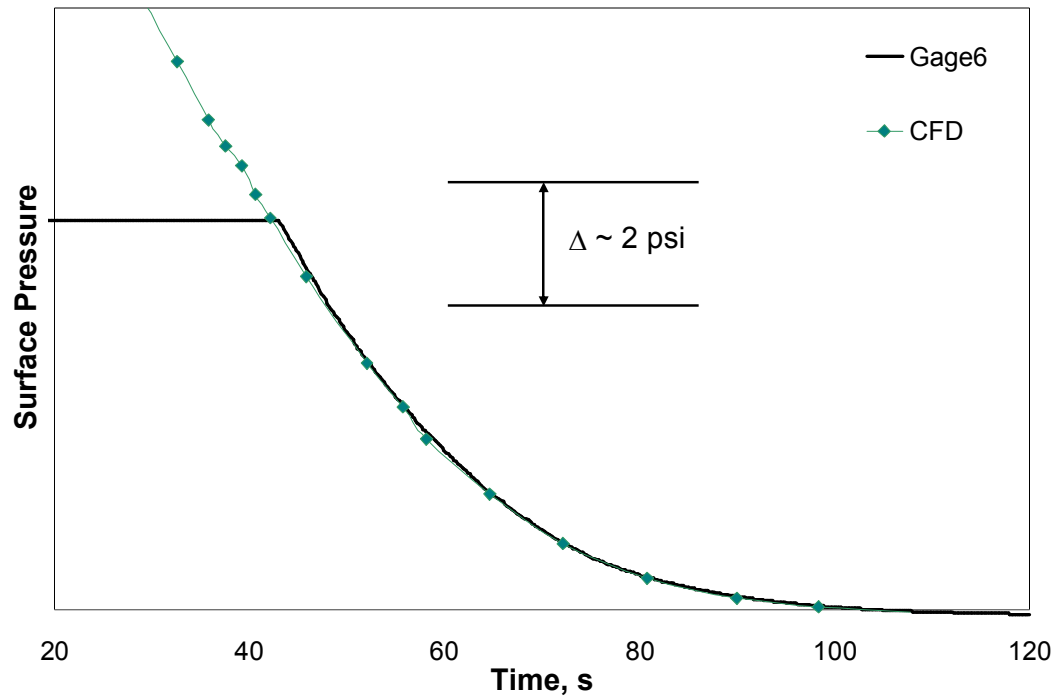

Figure 6. Comparisons of Gage6 and CFD

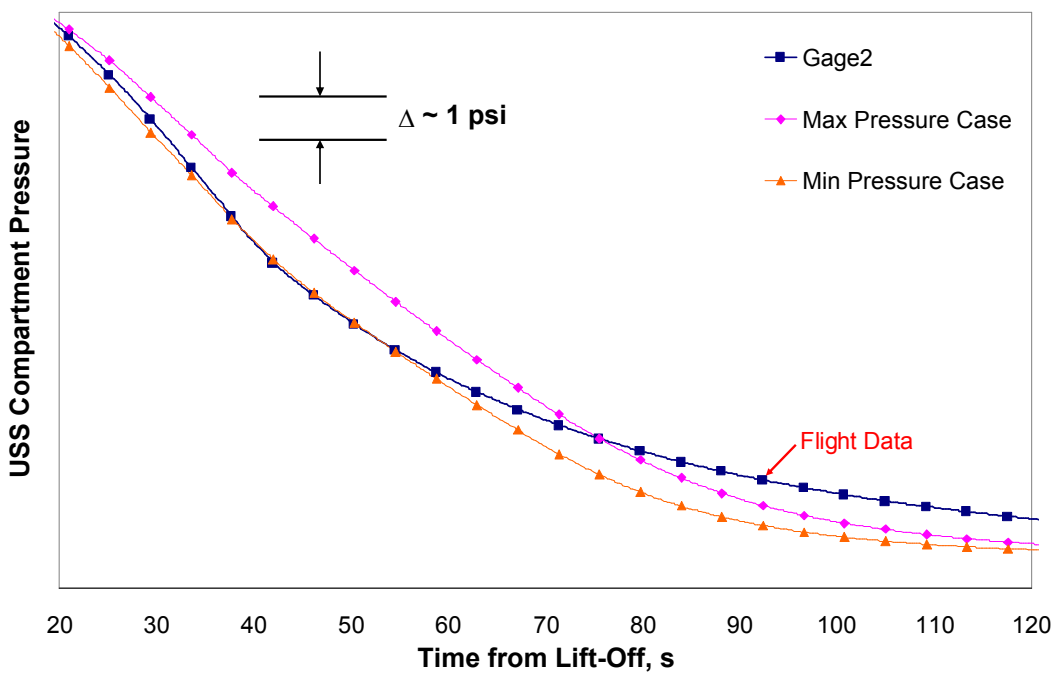

Figure 7. USS compartment pressures versus flight time measured data thereafter. Also from these figures, it can be observed that pressures from the minimum pressure case were below the flight data with the exception of the transonic region; differences between flight data and predictions at that time were less than 0.1 psi. Comparisons of flight measurements to the pre-flight predictions and a more detailed description of the ascent venting flight evaluation task can be found in Reference 6 . 


\section{Discussion: Differences between Predictions and Flight}

The "design band" approach led to successful bounding of the measured USS compartment pressures for most of the first minute of flight. The differences observed thereafter were of concern and efforts were undertaken to understand the reason(s) for their existence. Although the compartment volume, vent area, local external pressures, and potentially blocked vent(s) were possible contributors to the differences, it was concluded that the vent crossflow discharge coefficients used and the suspected reduction in vent area due to the flapper door were the most likely reasons for the observed differences.

\section{A. Estimation of Sonic Flow Vent Area}

Ideal flow through an orifice reaches sonic conditions at a pressure ratio of $\mathrm{P}_{\mathrm{C}} / \mathrm{P}_{\mathrm{L}}=1.89 \quad(\gamma=7 / 5)$. Data from Gage 2 and the average external pressures at the eight vents were used to estimate vent pressure ratios during flight to see if sonic conditions were reached. The resulting ratios are plotted in Figures 9 and 10 for the minimum and maximum pressure analysis cases, respectively. Also included in both figures are vent pressure ratios based on CHCHVENT predicted compartment pressures. These figures indicate that sonic conditions in the vents occurred after approximately 65 to 75 seconds

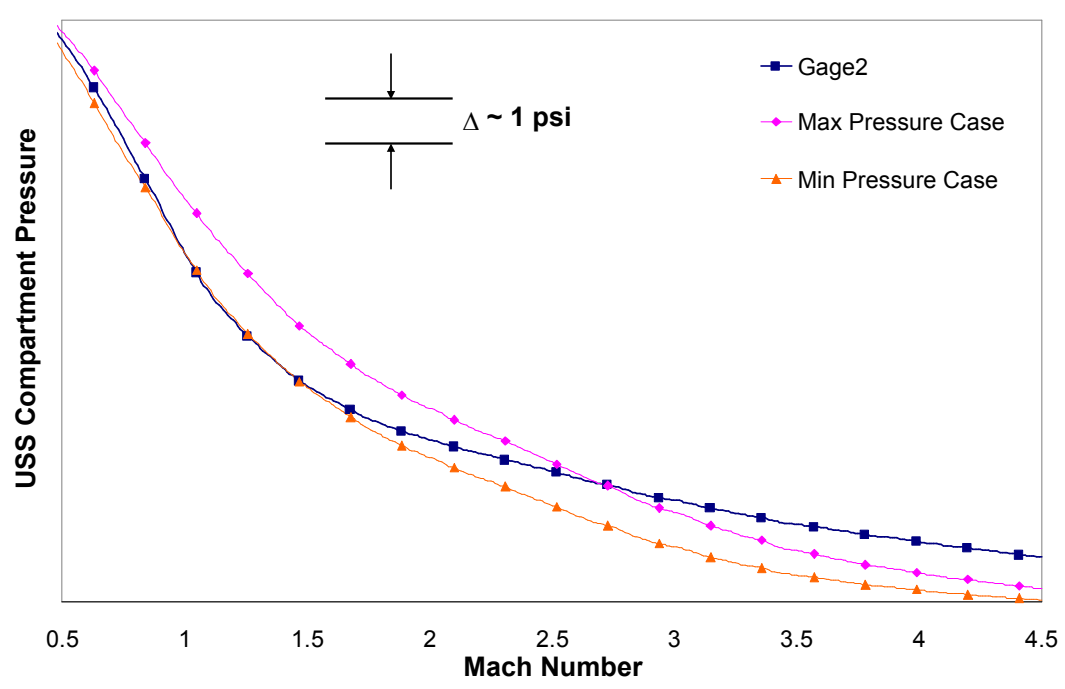

Figure 8. USS compartment predictions versus Mach number into flight. It should be noted that the minor differences in the calculated ratios using the measured compartment pressures (i.e., the first data series in each figure) are the result of the slightly different approaches used in extracting external pressure data from the CFD solutions for the two different analysis cases.

Sonic conditions prevailed for most of the time that flight pressure measurements were deviating from predictions. Consequently, efforts were made to estimate the vent area under sonic conditions and compare to the vent area used in CHCHVENT. The sonic flow area was estimated using Eq. (3)

$$
A^{*}=\frac{\dot{m} \sqrt{\gamma R T_{c}}}{\gamma C_{d} P_{c}}\left(\frac{\gamma+1}{2}\right)^{\frac{\gamma+1}{2(\gamma-1)}}
$$

The vent mass flow rate, discharge coefficient, and compartment pressure and temperature time histories were needed to calculate the sonic flow area time history using Eq. (3). Measured compartment pressures (i.e., Gage2) and measured temperatures from the thermocouple mounted on the vent housing (i.e., Gage4) were used with the ideal gas equation to "reconstruct" the time rate-of-change of mass $(\mathrm{dm} / \mathrm{dt})$ inside the compartment, which also represents the total mass flow rate history through all eight vents. The results of this exercise are displayed in Figure 11, where the total vent mass flow through all eight vents is displayed as a function of time from lift-off. The first data series represents the mass flow rate reconstructed from flight measured pressures and temperatures. The second and third data series in Figure 11 represent similar reconstructions using temperatures from CHCHVENT assuming an adiabatic and isothermal expansion, respectively. The last two data series represent the total vent mass flow rates as predicted by CHCHVENT. Beginning at approximately 1 minute into flight, it can be observed that the vent mass flow rates predicted by CHCHVENT are higher than the reconstructions, indicating that the effective vent area (i.e., $C_{d} \cdot A$ ) was smaller than what was calculated and used by CHCHVENT.

It should be noted that the additional vent mass flow rate reconstructions using the adiabatic and isothermal temperatures from CHCHVENT were investigated (and included in Figure 11) because the thermocouple, Gage4, 
was mounted to the exterior of the vent housing rather than being positioned in the exiting gas stream. The preferred compartment gas temperature measurement was the requested internally mounted GTP, Gage3, but data from that gage was compromised because a reference junction was not implemented. Preliminary analyses indicate, however, that expected errors in Gage 2 as a result of the mounting scheme may be small. This implies that the gas expansion within the compartment may actually have been more nearly isothermal than adiabatic, as the measurements indicate.

The cross-flow discharge coefficients used in Eq. 3 were based on the minimum pressure analysis case. An average pressure ratio was estimated using flightmeasured USS compartment pressures and average external vent pressures from the BET-specific CFD solutions. The vent local Mach numbers used in estimating the discharge coefficients were calculated assuming local (boundary layer edge) total pressures to be equal to the freestream total pressure

Figure 11 depicts total flow rates for all eight vents; therefore, oneeighth of the rates from the first series were used to reconstruct the choked flow area for one vent. The result is provided in Figure 12. The reconstructed choked flow area begins at 65 seconds because this is the approximate time when the vent pressure ratios reached sonic conditions (see Figures 9 and 10). The constant area for one vent that was used in the CHCHVENT analytical models is also included in Figure 12 for reference. The reconstructed choked flow area is approximately one-half of the analytical value which supports the notion that the vent areas were possibly reduced by the one-way flapper doors.

\section{Lessons Learned}

DFI that is dedicated to characterizing ascent venting environments is recommended for all future flight test vehicles. Redundant appropriately ranged sensors for internal compartment pressures, internal compartment temperatures, and local external vent pressures are recommended. Two (redundant) internal compartment pressure measurements were obtained during Ares I-X flight (Gage1 and Gage2). Prior to flight, an anomaly occurred with Gagel during DFI testing. However, this measurement appeared to provide good data because the resulting pressures were within the tolerance band of the data from Gage2. If Gage1 had been the only internal pressure measurement, the flight data would have been highly questionable. Since the two measurements resulted in similar compartment pressures, confidence that the measured pressures represented the actual pressures in flight is high. 
If vents are anything more complicated than simple holes in the skin, flight instrumentation should be sufficient to verify their proper operation and detect internal malfunctions. Specifically, any moving parts within the vent assembly should be instrumented to ascertain their position during flight.

In the analytical predictions, local pressures at the vents were defined using CFD solutions. As part of this evaluation, comparisons of measured external pressures to the CFD solutions resulted in good agreement. However, due to the importance of this input, it is recommended that pressures near the vents be measured during flight for validation purposes.

Based on the efforts to-date, it was concluded that inadequate modeling of the flow characteristics of the vents was the primary cause for the differences between the analytical predictions and the measured flight data. Therefore, for future applications it is recommended that characteristics of the vent flow be defined under flight conditions. This requires early development of vent designs so flow characterization activities can be accomplished in a timely fashion. Compartment vents are typically used for both on-pad purge operations and, more importantly, to minimize differential pressures during ascent. The flow characteristics need to be understood

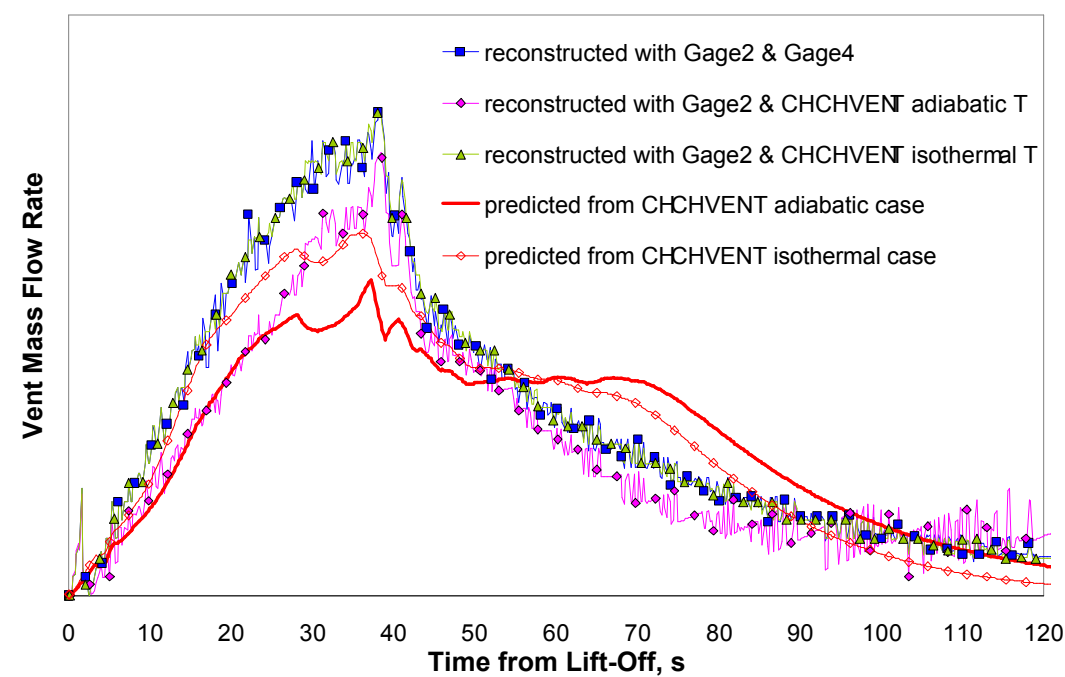

Figure 11. Reconstructed vent mass flow rates

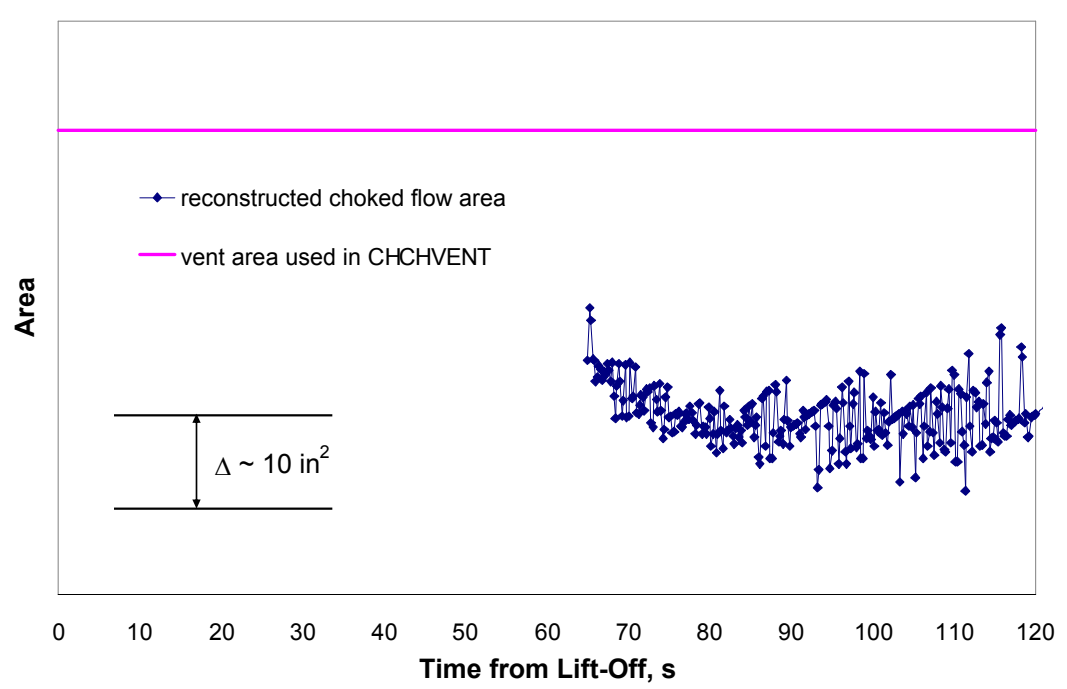

Figure 12. Analytical and reconstructed choked flow vent areas for both situations. Vent designs can include multiple elements that are located in close proximity to one another resulting in the need for CFD analysis and/or tests to characterize these complex flows.

\section{Future Work}

During review of this flight evaluation task with the Ares Aerodynamics Panel, the isentropic methods used by CHCHVENT to estimate the vent local Mach number were discussed. Investigations into that approach are continuing and any changes will be incorporated into the computer program.

Differences between the Ares I-X flight measured external surface pressures and the CFD data were not analyzed. It is possible that these differences could be used in estimating uncertainty factors for use in future analyses; therefore, those differences will be evaluated.

Based on preliminary analysis of the wind tunnel test data from which the cross-flow discharge coefficients were derived, there appears to be trends relating discharge coefficient and boundary layer thickness. If the trends actually exist, re-formulating the discharge coefficients to also be a function of the boundary layer thickness should be investigated. Reductions in the analysis design bands would be the potential opportunity.

As discussed previously, the vent cross-flow discharge coefficients and/or vent area reduction by deflection of the flapper door are considered the likely causes of the discrepancies between predictions and measurements. 
However, attempts to verify these hypotheses have not been conclusive and thus require further work. These are summarized below.

Differences between measured and predicted compartment pressures were observed for local Mach numbers greater than two. A preliminary parametric study was conducted for $\mathrm{M}_{\mathrm{L}}>2$ to determine the sensitivity of compartment pressure to cross-flow discharge coefficient and found the compartment pressure to be relatively insensitive to $+/-30 \%$ perturbations in the discharge coefficient. This implies that the cross-flow discharge coefficients are not responsible for the discrepancies between flight and predictions.

The position of the flapper door is determined by a balance of opposing hinge moments. The aerodynamic moment (which is proportional to the dynamic pressure in the vent duct) attempts to open the door. The moment created by gravity and acceleration attempts to close the door. It was thus hypothesized that the combination of decreasing compartment pressure and increasing vehicle acceleration caused the apparent reduction in vent flow area. However, contrary to expectations, a large decrease in acceleration that occurred between 105 and $120 \mathrm{~s}$ after launch is not reflected in the reconstructed vent area calculations shown in Figure 12.

\section{Conclusions}

The goals of the ascent venting flight evaluation were to validate the approach being used to develop ascent venting environments for the Ares I integrated US compartments and make necessary adjustments to that approach based on the flight evaluation. Based on the comparisons of predicted and measured USS pressures, it is believed that the methods being used were at least partially validated. Lessons learned were identified and recommendations have been made that are applicable to any launch vehicle. Other potential improvements to the process that were not fully explored as part of the flight evaluation have been listed under Future Work.

The design methodology being used for Ares I resulted in successful bounding of the Ares I-X USS measured compartment pressures for most of the first minute of flight. After the first minute, analytical predictions yielded faster depressurization of the USS compartment than was measured. This and other discrepancies between the flight data and predictions were attributed to inadequate modeling of the vent flow characteristics and use of thin-plate, circular orifice cross-flow discharge coefficients for a more complex vent design.

Reconstructions of the time rate of change of compartment mass using flight measured compartment pressures and three possible compartment temperature histories resulted in reconstructed sonic flow vent areas that were much smaller than what was used in the analytical models. This evidence supports the idea that the vent area was potentially reduced during flight due to choked flow at the vent flapper door, but it is not conclusive.

It is recommended for future flights that all input data used in the definition of compartment venting environments be characterized/validated using analytical and/or experimental methods such as CFD analyses and wind tunnel testing. Specifically, the effects of flow restrictions in the vents such as flapper mechanisms, check valves, transitions, bends, and interactions thereof should be characterized for all flight environments. In addition, use of thin-plate, circular orifice cross-flow discharge coefficients to model more complex vent designs should be validated. The resulting higher fidelity inputs would not only decrease the uncertainties in the overall analysis but also allow reductions in the venting environment design bands.

\section{Acknowledgments}

The authors want to thank Mr. Steven Bauer/Aerospace Engineer-NASA Langley Research Center for completing and making available the Ares I-X BET-specific CFD solutions.

\section{References}

${ }^{1}$ Frankenfield, B., “Ares I-X Upper Stage Simulator (USS) IPT Ascent Venting,” NASA Glenn Research Center, Rept. GRCARES-I-X-ANLS-125 Rev. A, Cleveland, OH, 14 Aug. 2008.

${ }^{2}$ Fay, J. F., "Program CHCHVENT Version 5 User's Manual and Software Description," Sverdrup Technology, Inc. MSFC Group, Rept. 631-001-93-007, Huntsville, AL, Nov. 1993.

${ }^{3}$ Walters, W. P., Glasgow, R. M., and Baker, J. M., "Experimental Determination of Generalized Venting Characteristics," NASA CR-61241, July 1968.

${ }^{4}$ Haukohl, J., Forkois, J. L., and Robertson, S. J., “Orifice In-flow Efficiency Tests,” NASA CR-61383, Mar. 1972.

${ }^{5}$ Perry, J. A., "Critical Flow Through Sharp-Edged Orifices," Transactions of the AMSE, Vol. 71, No. 7, Oct. 1949, pp. 757764.

${ }^{6}$ Ares Flight Evaluation Working Group (FEWG), "Final Flight Evaluation Report For Ares I Use of Ares I-X Data," NASA George C. Marshall Space Flight Center, Rept. APO-1041-04(volume 4) DRAFT, Huntsville, AL, Nov 2010. 


\title{
Ares I-X Upper Stage Simulator Compartment Pressure Comparisons during Ascent
}

\author{
William J. Downs \\ NASA Marshall Space Flight Center \\ Aerosciences Branch (EV33) \\ William.J.Downs@nasa.gov \\ 256-544-6398
}

49th AIAA Aerospace Sciences Meeting

4-7 January 2011 


\section{Paper Co-Authors}

\section{Robert D. Kirchner}

Qualis Corporation/Jacobs ESTS Group Aerosciences Branch (EV33) 256-544-5633

Robert.D.Kirchner@nasa.gov

\section{Blair G. McLachlan}

NASA Ames Research Center

Experimental Aero-Physics Branch 650-604-0944

Blair.G.McLachlan@nasa.gov
Lawrence A. Hand

NASA Ames Research Center

Experimental Aero-Physics Branch 650-604-1646

Lawrence.A.Hand@nasa.gov

\section{Stuart L. Nelson}

NASA Marshall Space Flight Center

Aerosciences Branch

256-544-1652

Stuart.L.Nelson@nasa.gov 


\section{Outline}

- Objective

- Compartment Venting Background

- Venting Environments Development Approach

- Ares I-X USS Venting Configuration and Flight Instrumentation

- Comparisons of Flight Data and Analytical Predictions

- Possible Reasons for Differences between Flight Data and Predictions

- Lessons Learned

Summary 


\section{Objective}

- The objective of this paper is to

- Present comparisons of Ares I-X Upper Stage Simulator (USS) internal compartment pressures measured during flight to analytical predictions using methods employed for Ares I environment development

- Provide potential reasons for the observed differences in flight data and predictions

- Summarize lessons learned and provide recommendations for future flight vehicles 


\section{Compartment Venting Background}

- Launch vehicle compartments (interstages, systems tunnels, etc.) are vented primarily to

- Provide escape of purge gases while on the pad and

- Minimize differential pressure loads across the skin during ascent

- Transient venting analyses provide internal compartment pressures during ascent

- Can combine with local external pressures to yield differential pressure loads

- Compartment venting is important Skylab workshop venting failure

- Meteoroid shield torn from vehicle during ascent, causing subsequent loss of solar array wing \#2 during retrorocket firing and failure of wing \#1 deployment

- Most probable failure mode was from excessive internal pressure in the auxiliary tunnel, causing meteoroid shield to be pushed into supersonic airstream and stripped away

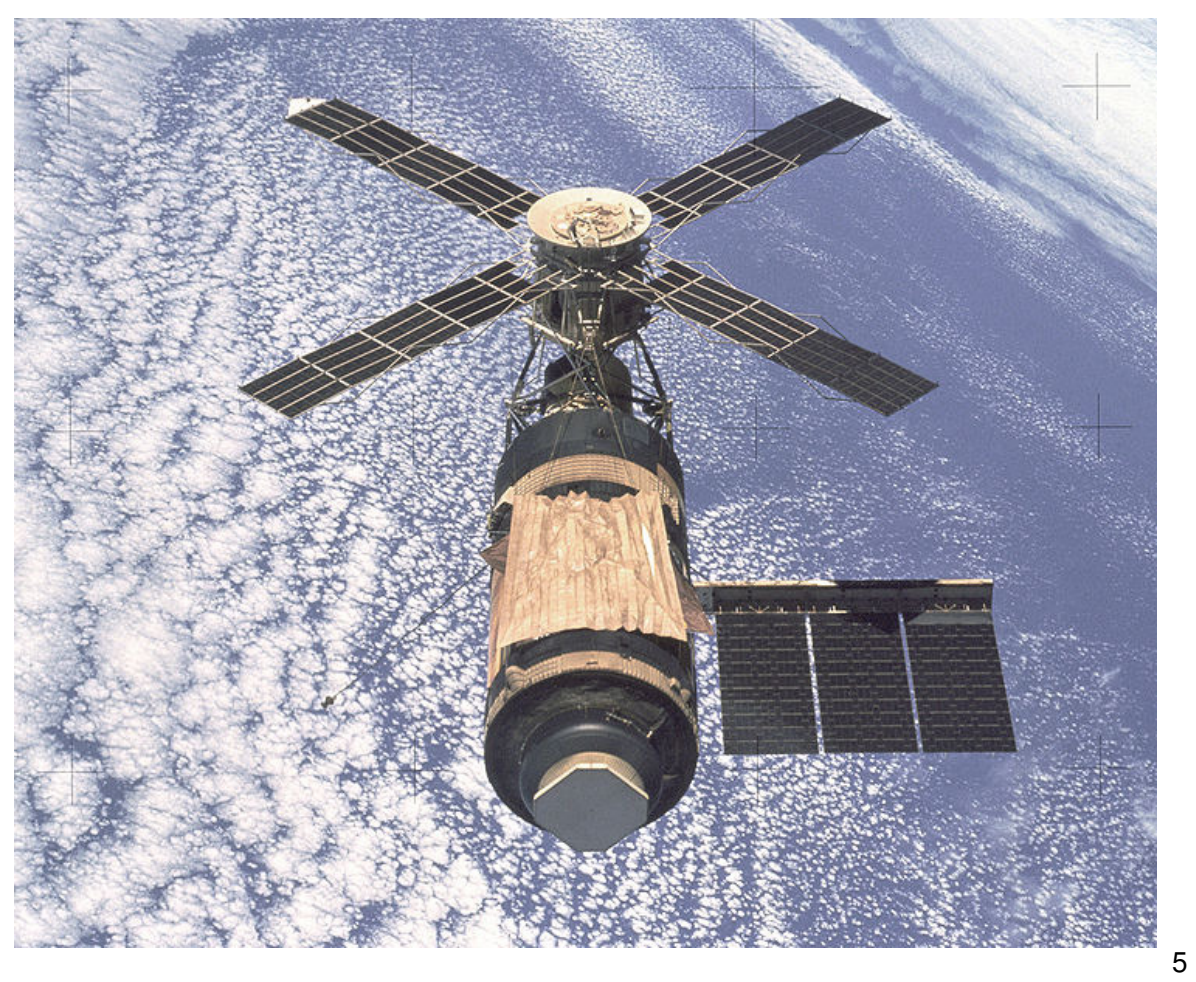




\section{Venting Analysis Methods}

Venting analysis computer program CHCHVENT

- Network analysis simulates the flow of ideal gases through interconnected chambers and vents

- Developed in early 90's by Dr. John Fay/Sverdrup while under contract to MSFC

- Also used for analysis of expendable launch vehicles (ELVs), Space Transportation System (STS) Solid Rocket Boosters (SRBs), and First Stage of Ares-I

- Conservation of mass and energy equations

- 1-D isentropic mass flow rate corrected with user-specified discharge coefficient models

- Inputs required include trajectory, vent local pressures, compartment geometry, and flow characteristics of the vents

- For Ares I-X USS analyses used

- Ares I-X Best Estimated Trajectory (BET)

- Local vent pressures from Ares I-X configuration BET-specific CFD solutions

- Compartment information obtained from design group

- Cross-flow discharge coefficients based on previously conducted wind tunnel tests of thin-plate circular orifices with varying boundary layer thicknesses 


\section{Venting Analysis Methods (cont.)}

- Two analysis cases used to develop design venting environments

1. Maximum pressure case

- Internal compartment pressures are maximized and can be coupled with minimum external pressures to yield maximum skin differential pressures

2. Minimum pressure case

- Internal compartment pressures are minimized and can be coupled with maximum external pressures to yield minimum skin differential pressures 


\section{Ares I-X Vehicle and USS Compartment}

- Ares I-X USS was one compartment that extended from the tip of launch abort system simulator to the first stage

- Ares I integrated Upper Stage consists of multiple compartments

- Scope was USS compartment only

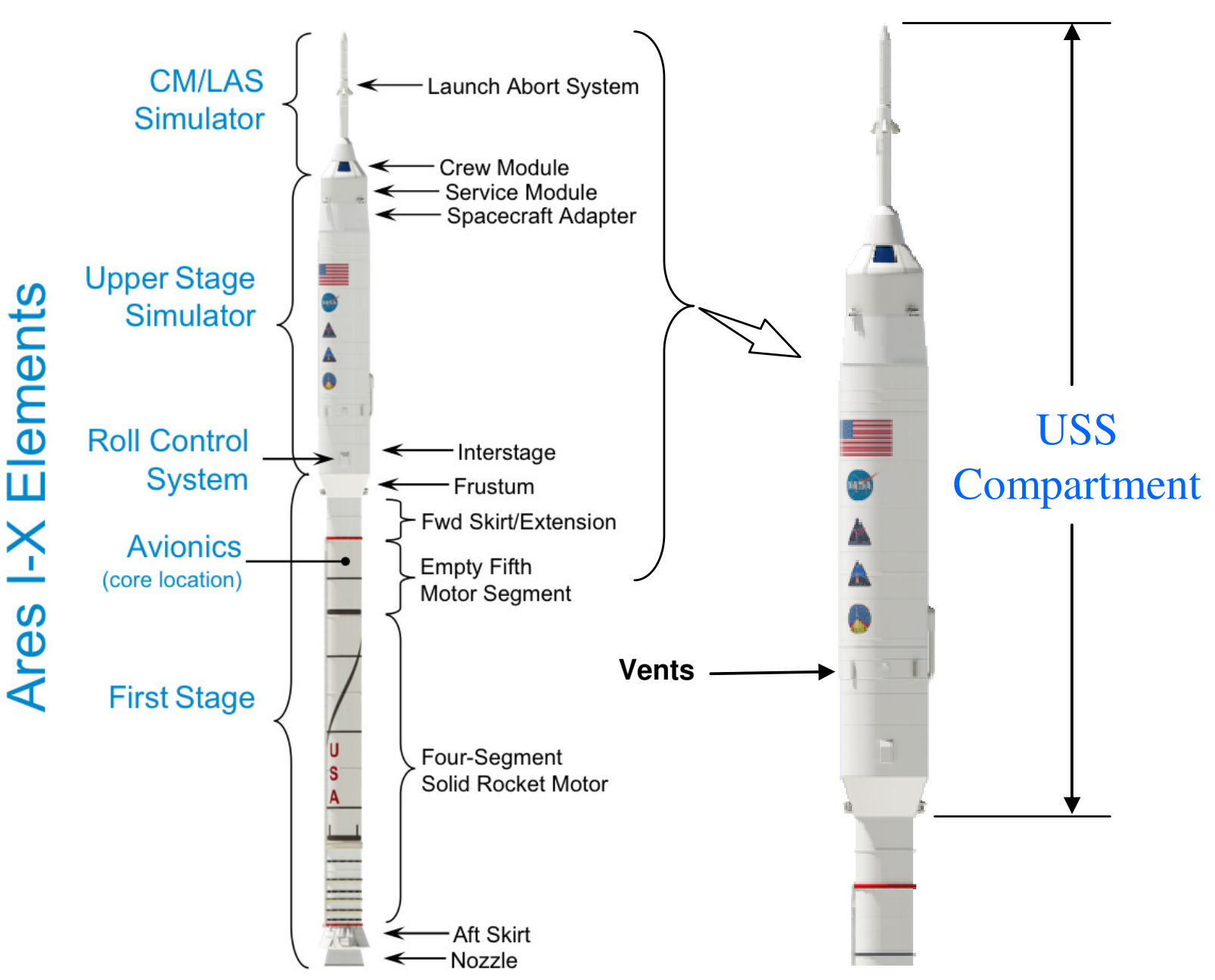




\section{Ares I-X USS Compartment Vents}

- 8 vents distributed evenly around the circumference

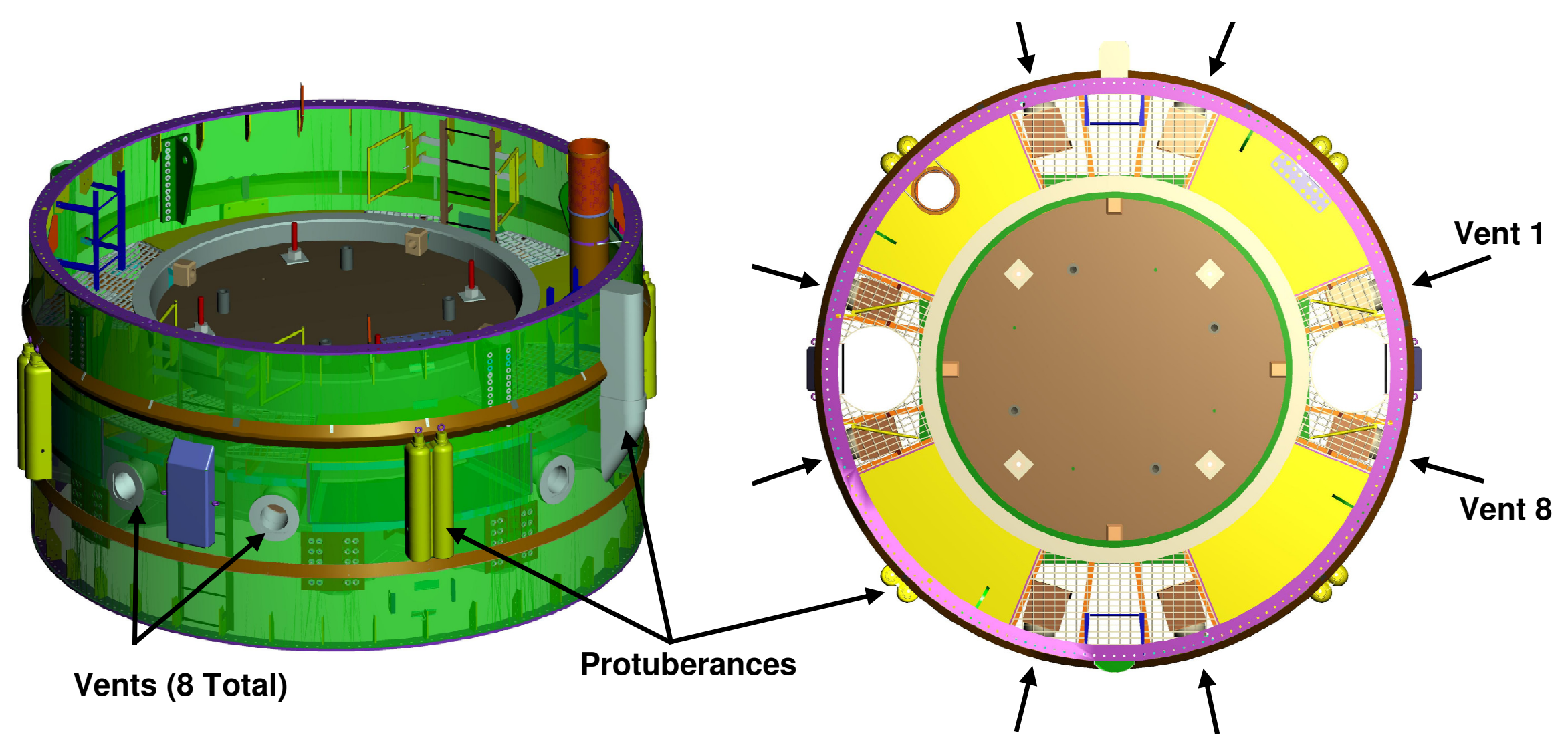




\section{Ares I-X USS Compartment Vent Assembly}

\section{- Vent assembly design}

- Rectangular entrance duct transitioned to circular cross-section

- Free-hanging flapper door

- Screen at outer mold line

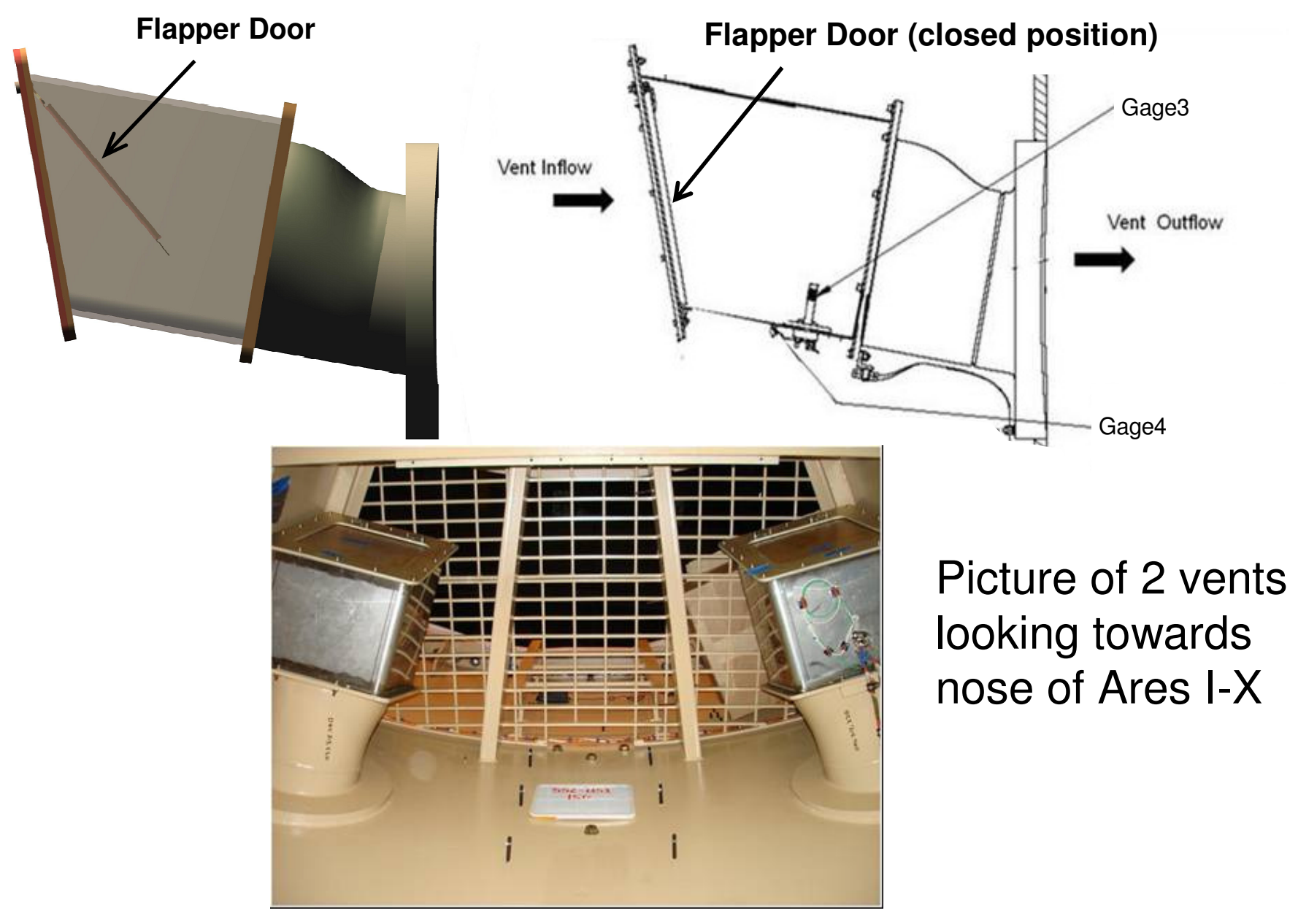




\section{Developmental Flight Instrumentation (DFI)}

- 6 flight measurements were considered

- 2 internal compartment pressures

- 1 thermocouple mounted on vent housing

- data from Gage3 (gas temperature probe) was bad

- 2 external surface pressures

\begin{tabular}{|l|c|c|c|}
\hline \multicolumn{1}{|c|}{ Sensor } & Body Part & Location & Sensor Type \\
\hline Gage1 & USS compartment & interior & pressure \\
\hline Gage2 & USS compartment & interior & pressure \\
\hline Gage3 & vent assembly & duct interior & gas temp probe \\
\hline Gage4 & vent assembly & duct surface & thermocouple \\
\hline Gage5 & US segment & surface & pressure \\
\hline Gage6 & US segment & surface & pressure \\
\hline
\end{tabular}

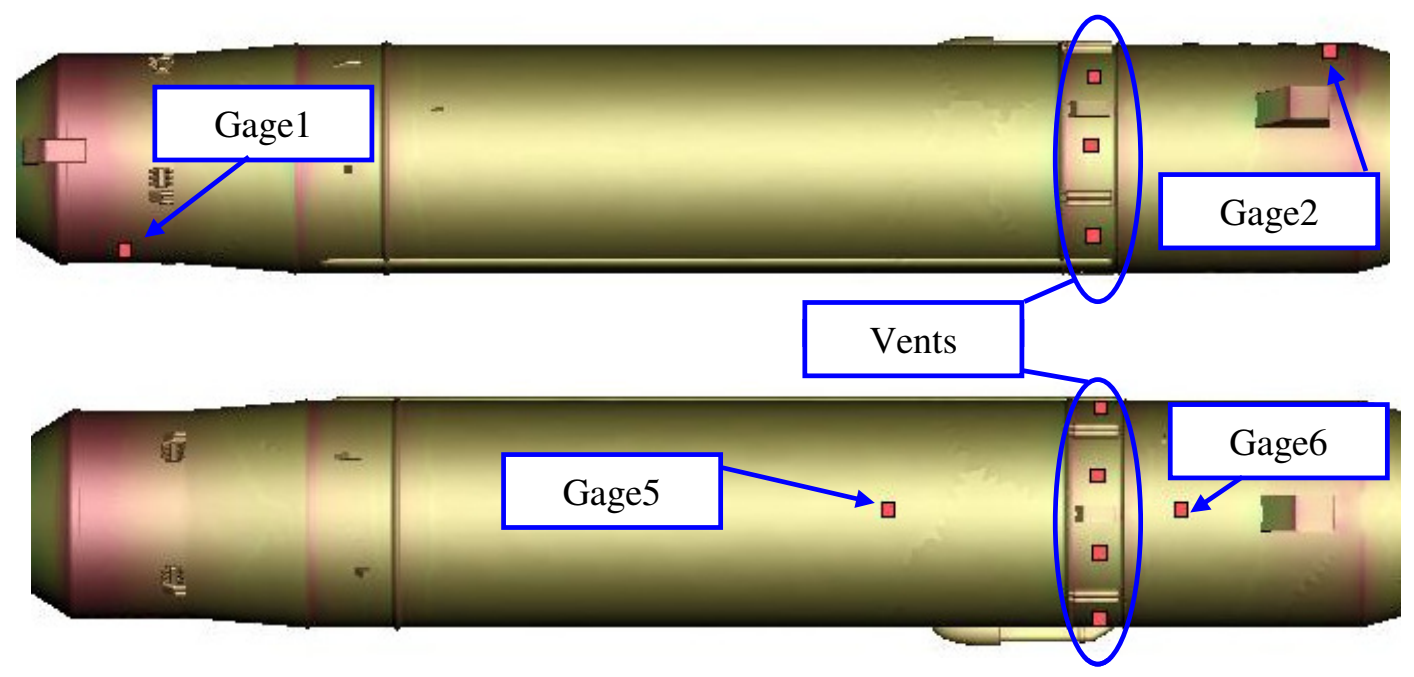




\section{Flight Data vs. CFD Surface Pressures}

- Local external vent pressures are an important input to the venting analysis

- Pressures in the immediate vicinity of the vents were not measured during flight

- Comparisons of CFD data to sensors requested by aerothermal team were made

- Sensors had limited range resulting in flatline data during initial flight phase

- Comparisons after initial flight phase favorable
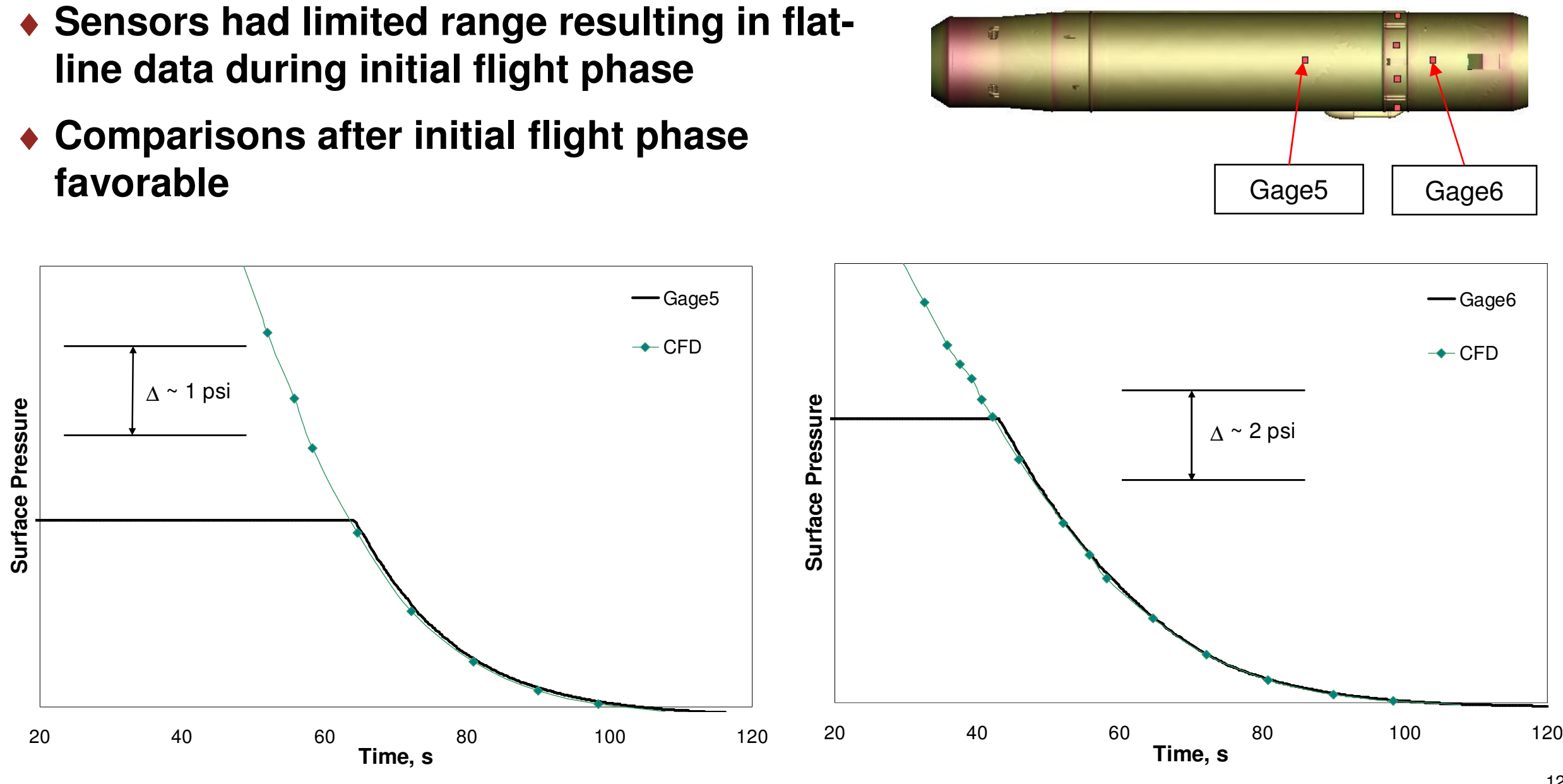


\section{USS Internal Compartment Pressures}

Predictions vs. Flight Data

- Predictions based on post-flight venting analyses with latest inputs

- BET trajectory \& AIX BET-specific CFD solutions for vent external pressures

- Max pressure case bounds flight data for first minute of flight; deviates thereafter

- Min pressure case bounds flight data except @ 40-50 seconds (<0.1 psi difference)
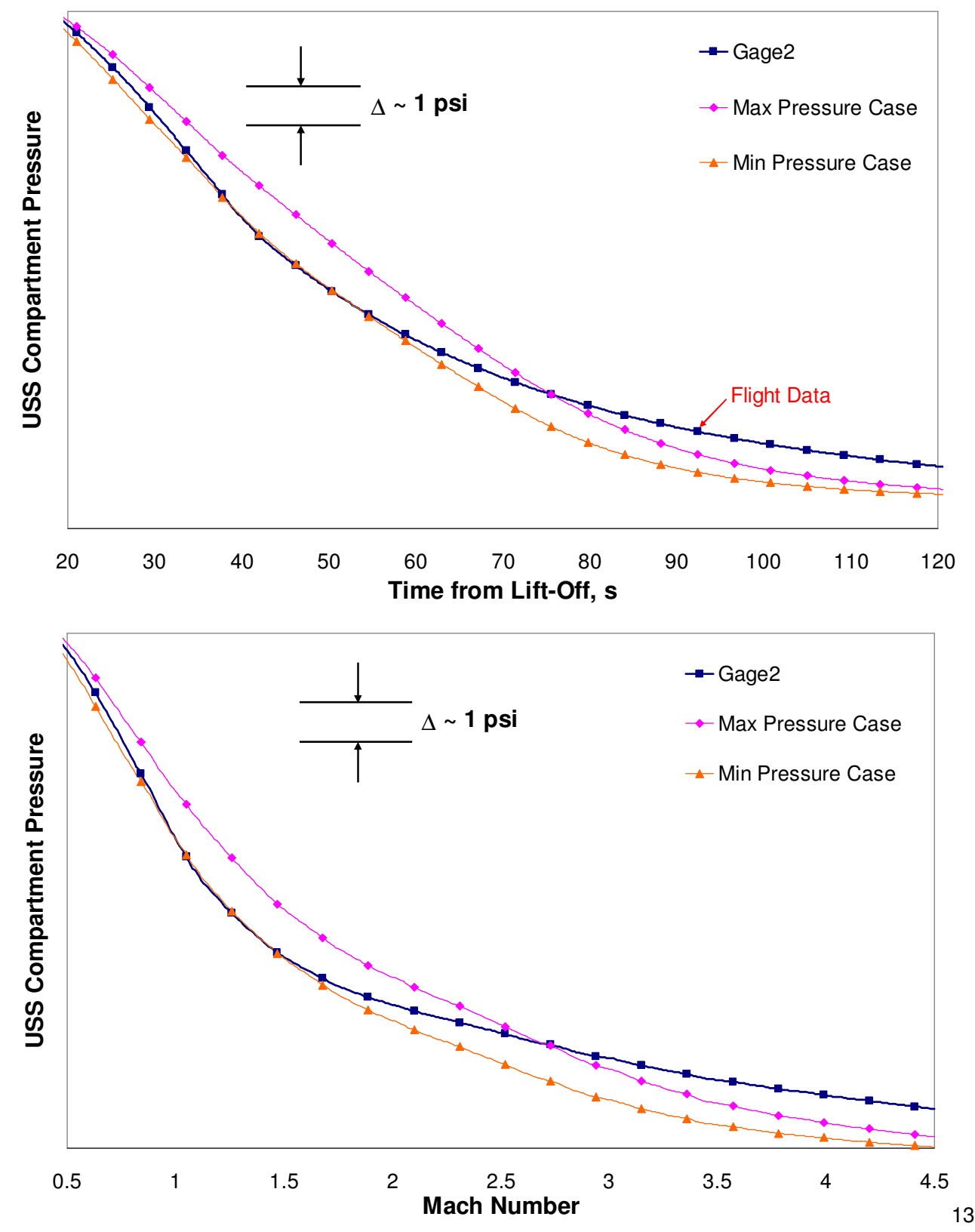


\section{Potential Reasons for Differences}

Between Predictions and Flight Data

\section{- Compartment Volume}

- Data obtained from design group and analyses were completed where the volume was perturbed $10 \%$ and the effects were small relative to the observed differences; therefore believe little to no factor in differences

\section{- Vent Area}

- Data obtained from design group and drawings

- Estimated effective vent exit area based on screen porosity

- Believe little to no factor in differences between flight data and predictions

\section{- Vent(s) Blocked}

- Analysis completed with 1 and 2 vents blocked beginning at 40 seconds

- Resulting pressures approached the flight data as expected but trends did not match measured flight characteristics

\section{- Vent Pressures}

- No flight data was obtained near the vents. Comparisons of CFD pressures to pressures (flight data) in other locations favorable.

- Contribution to differences believed to be small 


\section{Potential Reasons for Differences}

Between Predictions and Flight Data

\section{- Discharge Coefficients}

- Believed to be a potential contributor to the differences

- Using thin-plate, circular orifice $\mathrm{C}_{\mathrm{d}}$ values for the more complex Ares I-X vent design has not been validated

- Vent Design - Reduction in flow area due to flapper mechanism

- Believed to be potential contributor to differences between predictions and flight data

- Observations believed to be caused by the flapper mechanism

- Sudden reduction in rate at which compartment pressure decreases relative to predictions after vent assembly reaches sonic conditions $(\mathrm{Pc} / \mathrm{Pl}>1.89$, $\mathrm{Mach}=1)$

- Reduction in vent mass flow rates below predictions after vent assembly reaches sonic conditions

- The vent dynamic pressure on the upstream side of the flapper decreases during ascent. This, in combination with vehicle acceleration (tending to shut the flapper), also supports hypothesis of flapper potentially reducing flow area.

- Additional analysis (CFD and/or testing) is needed to determine characteristics of the flapper 


\section{Sonic Conditions in the Vents}

- Pressure ratios across the vents were checked for choked condition

- $\mathrm{P}_{\mathrm{C}} / \mathrm{P}_{\mathrm{L}}=1.89$

- Since sonic conditions occurred at time of deviations of predictions and measurements, vent area estimated under sonic conditions

$$
A^{*}=\frac{\dot{m} \sqrt{भ R T_{c}}}{\chi_{d} P_{c}}\left(\frac{\gamma+1}{2}\right)^{\frac{\gamma+1}{2(\gamma-1)}}
$$

\section{Inputs to equation}

- Flight measured pressures and temperatures

- Cross-flow discharge coefficients used for minimum pressure analysis case

- Reconstructed mass flow rate using measured compartment temperature
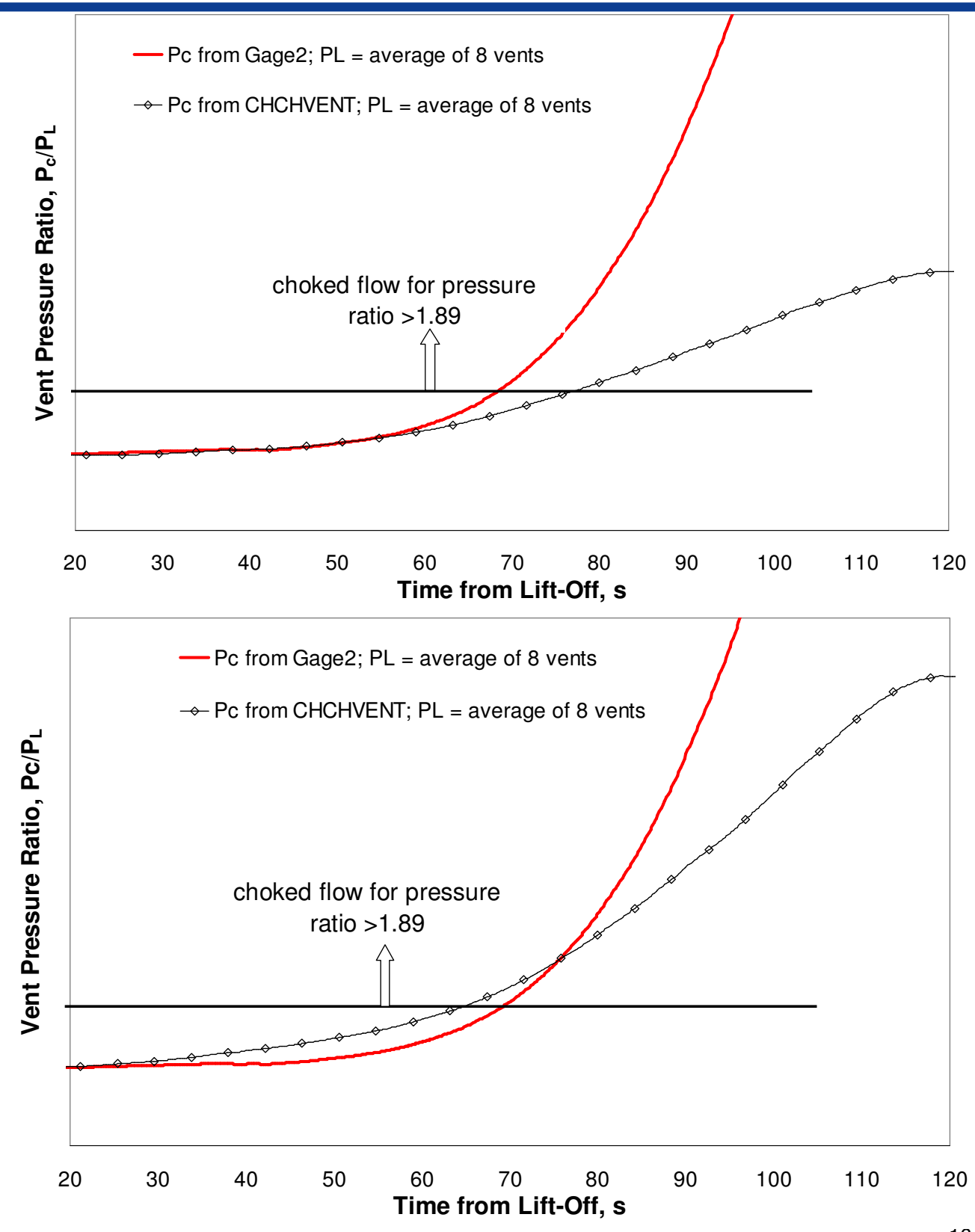


\section{Reconstructed Mass Flow Rate}

- Vent mass flow rates reconstructed for 3 assumed temperatures and compared to CHCHVENT

- Predicted higher flow rates beginning near 60 seconds suggest smaller actual effective areas (i.e., Cd.A) than modeled

- Reconstructed area is $~ 1 / 2$ the modeled area, supporting notion that vent areas were possibly reduced by the flapper doors

- Observation that does NOT support area reduction due to flapper door

- A large decrease in vehicle acceleration that occurs between 105 and $120 \mathrm{~s}$ after launch is not reflected in the reconstructed vent area
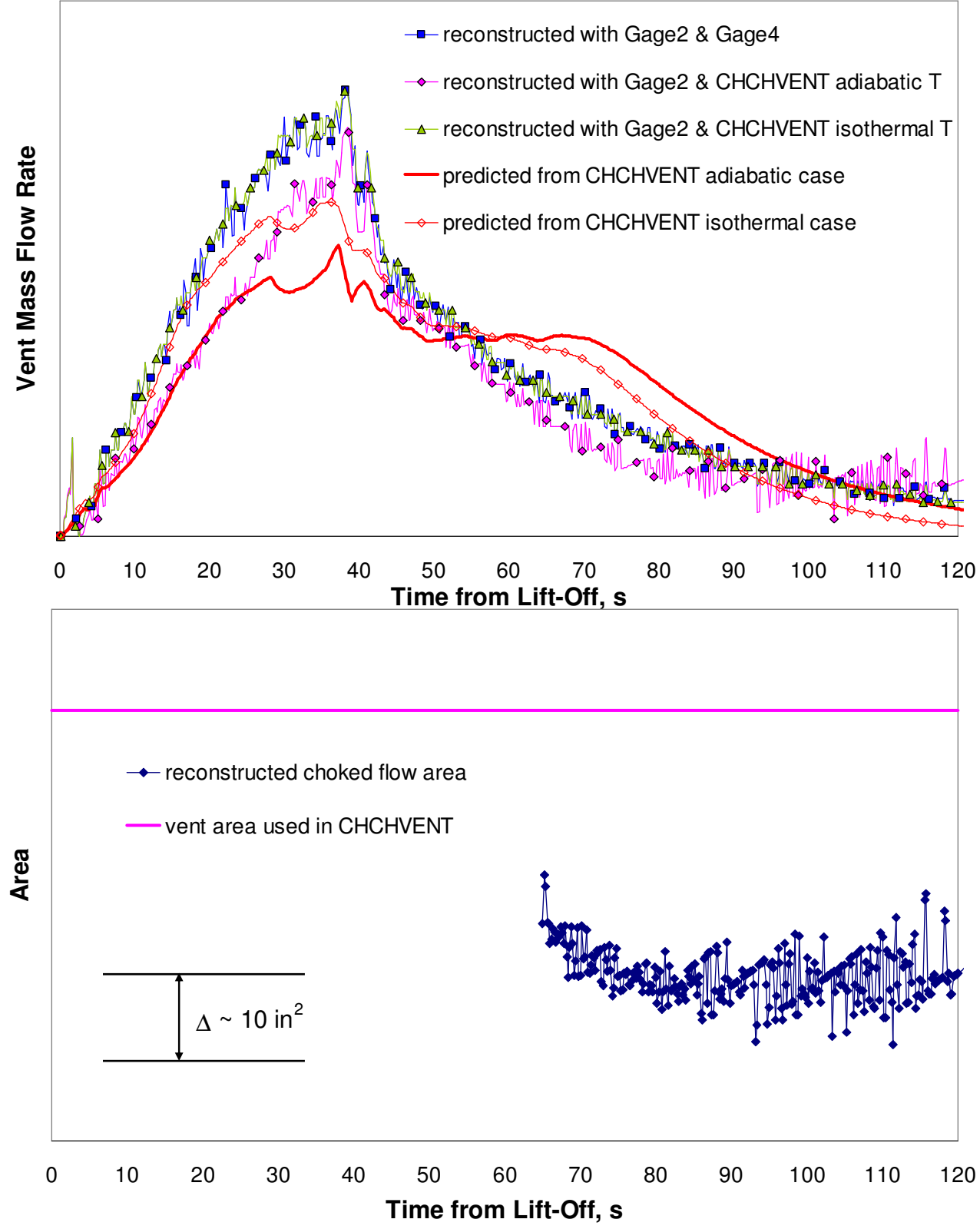


\section{Lessons Learned}

- Flow properties of vent designs need to be defined

- Effects of flow restrictions (flapper mechanisms, turns, bends, and interactions thereof) should be characterized

- Use of thin-plate, circular orifice cross-flow discharge coefficients for more complex vent designs should be verified

- Potentially accomplished with CFD analysis

- Analytical approach to determining local Mach number at the vents should be verified (input parameter to discharge coefficients)

- Analysis on-going into how calculations are presently made

- Future flight tests should include

- Redundant sensors dedicated to ascent venting environments definition

- Compartment pressures, temperatures, and gas temperature probes

- External pressures near the vents

- Comparisons to CFD data were good, but recommended for validation purposes

- Representative

- Compartment volumes, vent areas, and vent designs 


\section{Summary}

- Design environment methodology using for Ares-I resulted in favorable bounding of Ares I-X measured flight internal pressures for most of the first minute of flight

- Maximum pressure case did not bound flight data after first minute

- Minimum pressure case did not bound flight data between 40-50 seconds ( $<0.1$ psid)

- Discrepancies between predictions and flight data are attributed to inadequate modeling of the vent (flapper door) and the discharge coefficient models used

- Flow properties of vent designs (discharge coefficients, flow restrictions, etc.) should be characterized/validated by analytical and/or experimental methods (CFD analysis, wind tunnel testing, etc.)

- Goal to bound environment predictions as well as narrow the design bands 